\title{
Twinning in human populations and in cattle exposed to air pollution from incinerators
}

\author{
O L LLOYD,' M M LLOYD,' F L R WILliAMS,' A LAWSON ${ }^{2}$ \\ From the Environmental Epidemiology and Cancer Centre, ${ }^{\prime}$ Wolfson Institute of Occupational Health, \\ Department of Community Medicine, Ninewells Medical School, University of Dundee, and Department of \\ Mathematics and Computer Studies, ${ }^{2}$ Dundee College of Technology, Dundee, UK
}

ABSTRACT Human populations and animals are often exposed to the airborne pollutants in plumes from incinerators. The incineration of chemical and other waste may release polychlorinated hydrocarbons, some of which have oestrogenic properties. Increased numbers of twins had been reported anecdotally in cattle at risk from plumes from two incinerators near the town of Bonnybridge in central Scotland and also in cattle near a chemical factory in Eire. It was decided to follow up these reports in central Scotland and also to test the hypothesis that the frequency of human twinning might be increased there. Data on human twin and single births in hospitals in central Scotland were obtained for the years 1975-83. The twinning rates in areas exposed to airborne pollution from incinerators were compared with the background rates present in neighbouring areas. Farmers provided information on calving among the herds of two farms close to the incinerators. The frequency of human twinning was increased, particularly after 1979, in the areas most at risk from air pollution from the incinerators. Among the dairy cattle, there was a dramatic increase in twinning at about the same time.

During the late 1970 s and early 1980 s, public fears were expressed that pollutants from a chemical waste incinerator near the town of Bonnybridge in central Scotland were affecting the health of farm livestock and the local population. In 1985 an independent inquiry rejected industrial contamination from the incinerator as the cause of local patterns of disease in both people and animals.' Disturbing findings were noted in that report, however. Human health abnormalities included an apparent excess of eye defects among babies, a rise in the incidence of leukaemia and a statistically significant excess of death from bronchitis, a disease that has been linked with exposure to polychlorinated hydrocarbons (PCHs), ${ }^{23}$ and which is a priori probably the most useful indicator of consequences to health from airborne pollution. Among livestock at one farm in the area, the report noted, it was "unusual for one herd to have so many cases of each kind in so short a period and for them to be unresponsive to the forms of therapy that are usually appropriate."

The inquiry's report did not provide complete reassurance, partly because it contained design defects

Accepted 14 August 1987 and gaps. ${ }^{45}$ The failure of farm animals to respond to the conventional treatments also cast doubt on the official veterinary diagnoses which the inquiry had accepted. Local farmers have continued to experience problems, one farmer losing over 60 animals during the early months of 1986. Chemical assays have shown the presence of toxic chemicals such as metals and PCHs in the environments of local farms. ${ }^{16-8}$

The exact source and timing of the combustion and possible release of $\mathrm{PCH}$ related compounds is not clear. The two incinerators near Bonnybridge were a municipal incinerator that had operated for many years and a nearby chemical incinerator which began operating in 1974. With the latter, instructions on safety precautions relating to $\mathrm{PCHs}$ were issued to the workforce in 1975, and revised in 1976 and 1977 (ReChem International response to the Bonnyridge dossier, 1985); an official report on the incinerator stated that "since 1978 the rate a.t which PCBs" (polychlorinated biphenyls) "have been incinerated has been restricted." According to the company itself, no PCBs were burnt between 1977 and 1979 (response, 1985), but they were burnt regularly from $1980 .^{1}$ The lack of clear information about the timing of incineration specifically related to $\mathrm{PCHs}$, however, may be of 
secondary importance, since PCHs may be released from a wide range of industrial materials during combustion. ${ }^{10}$

Some PCHs have oestrogenic and fertility related properties ${ }^{11-13}$; either endogenous or exogenous oestrogens may affect the frequency of twinning. ${ }^{14}$ is In recent reports of the geographical association between complex chemical pollution and livestock losses in Eire, the frequency of twinning of calves was shown to have been raised. ${ }^{16}$ Although PCHs had been incinerated at Bonnybridge, and tissues from local cows had shown traces of PCHs and related dioxins, ${ }^{8}$ the phenomenon of twinning had not been investigated when the epidemiological picture at Bonnybridge was first compiled. Because an increased frequency of twinning might provide a sensitive and early indicator of environmental toxicity from this type of chemical, we tested the hypothesis that an association between twinning and chemical pollution would be found among the cattle and the inhabitants of areas near the incinerators near Bonnybridge.

\section{Methods}

For studying the geographical distribution of twinning during 1975-83 in the relevant area of central Scotland (postcode sectors FK1-16 and EH51) (fig), information on the numbers of single and twin births was obtained from the Information and Statistics Division of the Common Services Agency. (This information is thought to be about $98 \%$ complete for single births and slightly lower for multiple births.) The births were analysed by year of registration.

In central Scotland the maximal accumulation of air pollution is caused by the easterly winds which are associated with sluggish airflow and temperature inversions. The prediction that these winds would carry fumes from the incinerators westward to the

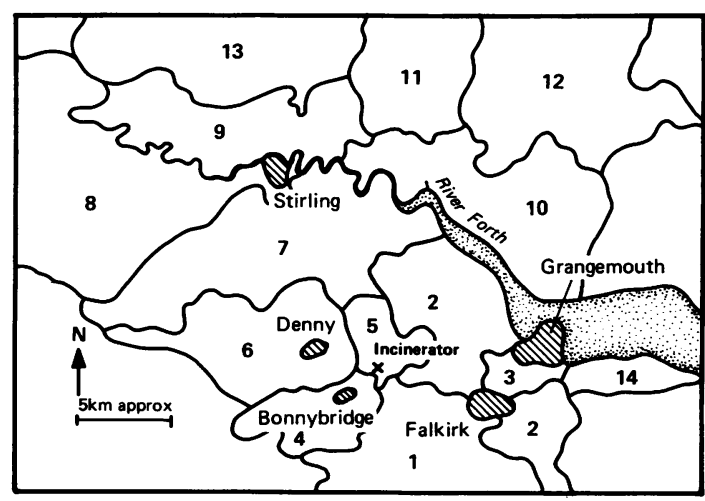

Central Scotland, showing locations of 14 areas based on postcode sectors and of site of incineration. postcode sectors FK4 and 6 was supported by the comparatively high concentrations of $\mathrm{PCHs}$ found in surface soils there. ${ }^{8}$ Hence these sectors constituted the areas of primary risk. The sectors of secondary risk, FK 5 and 2, were at risk from air pollution carried by the more vigorous southwesterly winds which are most prevalent in Scotland. The background values of twinning in the neighbourhood were provided by the rates in ten areas derived from the remaining 13 postcode sectors, sectors with fewer than 200 births during either period (see below) being amalgamated with adjacent sectors. The twinning rates were calculated for these 14 areas for two consecutive periods of equal duration: 1976-9 and 1980-3.

The pattern of twinning in the 14 areas between 1975 and 1983 was studied on an annual basis by two methods. Firstly, the annual twinning rates in those areas were calculated and ranked. Secondly, Moran's I coefficient for detecting spatial autocorrelation ${ }^{17}$ was used to detect spatial clustering or regularity in the mapped pattern. (The statistic may be tested as a standard normal variable: $Z=[I-E(I)] \div \sqrt{ }$ var (I). If large negative values of $Z$ are found the map displays regularity; large positive values denote clustering. Both types of value suggest non-randomness in the pattern. Values of $Z$ close to zero denote random map patterns.)

Because twinning rates increase considerably in mothers aged over $35,{ }^{18}$ the ages of the mothers of twins in the at risk sectors were compared with the ages of mothers of twins in the study area as a whole.

Lastly, two farmers with dairy farms within the primary at risk sectors, and whose problems had been reported previously, ${ }^{1}$ provided information on the numbers of twin and single births born to their herds during recent years.

\section{Results}

In the analysis of the geographical distribution (fig, table 1) of the rates of human twinning during 1976-9 and 1980-3 the ten areas providing background values for the neighbourhood showed rates in the range 3 to 13 per 1000 . By contrast, the highest values $(20$ and 16 per 1000) were found in the two primary risk sectors (FK6 and FK4 respectively) during 1980-3. Comparatively high values were present also in the two sectors of secondary risk: in FK 2 for both periods and in FK 5 for 1976-9 only. (For the purpose of the study the one triplet birth in FK6 in 1980 was counted among the twins.)

The rank order analysis of the annual values for twinning in the individual sectors (table 2) showed the emergence of high twinning rates in FK 5, followed by FK4 and FK6 during the late 1970s and early 1980s. No other geographically distinct area appeared with 
Table 1 Twinning rates, per thousand total births, in 14 areas (based on postcode sectors) of central Scotland during 1976-9 and 1980-3

\begin{tabular}{|c|c|c|c|c|c|c|}
\hline \multirow[b]{2}{*}{ Areas } & \multicolumn{3}{|l|}{ 1976-9 } & \multicolumn{3}{|l|}{$1980-3$} \\
\hline & No pairs twins & Total births & Rate/1000 & No pairs twins & Total births & Rate/1000 \\
\hline
\end{tabular}

Table 2 Rank order of twinning rates in 14 areas (based on postcode sectors) in central Scotland, 1975-83

\begin{tabular}{|c|c|c|c|c|c|c|c|c|c|}
\hline Rank & 1975 & 1976 & 1977 & 1978 & 1979 & 1980 & 1981 & 1982 & 1983 \\
\hline $\begin{array}{l}1 \\
2 \\
3\end{array}$ & $\begin{array}{l}11 \\
5 \\
4+2\end{array}$ & $\begin{array}{r}11 \\
2 \\
1\end{array}$ & $\begin{array}{l}5 \\
7 \\
9\end{array}$ & $\begin{array}{r}5 \\
12 \\
6\end{array}$ & $\begin{array}{l}2 \\
6 \\
5\end{array}$ & $\begin{array}{l}6 \\
4 \\
1\end{array}$ & $\begin{array}{r}9 \\
6 \\
11\end{array}$ & $\begin{array}{l}4 \\
13+2 \\
11+10\end{array}$ & $\begin{array}{l}6 \\
2 \\
3\end{array}$ \\
\hline
\end{tabular}

Where rates are equal the two values are denoted together with + .

Table 3 Moran's I statistic and Z score: a test for detecting spatial clustering of twinning in 14 areas (based on postcode sectors) of central Scotland between 1975 and 1983

\begin{tabular}{lllllllrrr}
\hline & 1975 & 1976 & 1977 & 1978 & 1979 & 1980 & 1981 & 1982 & 1983 \\
\hline I statistic & -0.372 & -0.311 & -0.059 & -0.154 & 0.196 & 0.353 & -0.073 & -0.103 & -0.079 \\
Z score & -1.85 & -1.46 & 0.107 & -0.481 & 1.709 & $2.689^{*}$ & 0.024 & -0.164 & -0.013 \\
\hline
\end{tabular}

*p $<0.01$ (2 tail test).

Table 4 Twin births for calves born on farm 1 in the primary at risk area near Bonnyridge from 1972 to 1985 , expressed as numbers and as percentages of all calvings

\begin{tabular}{|c|c|c|c|c|c|c|c|c|c|c|c|c|c|c|}
\hline & 1972 & 1973 & 1974 & 1975 & 1976 & 1977 & 1978 & 1979 & 1980 & 1981 & 1982 & 1983 & 1984 & 1985 \\
\hline $\begin{array}{l}\text { No } \\
\%\end{array}$ & 0 & 0 & 0 & 0 & 1 & 0 & $\begin{array}{l}2 \\
2\end{array}$ & $\begin{array}{l}3 \\
2\end{array}$ & $\begin{array}{r}12 \\
8\end{array}$ & $\begin{array}{l}18 \\
12\end{array}$ & $\begin{array}{l}26 \\
17\end{array}$ & $\begin{array}{l}31 \\
22\end{array}$ & $\begin{array}{l}14 \\
17\end{array}$ & $\begin{array}{r}3 \\
10\end{array}$ \\
\hline
\end{tabular}

such regularity in the highest ranks during the period of observation. The analysis of spatial autocorrelation (table 3) showed a progressive trend from a regular pattern in 1975, through a period of relative randomness in 1976-9, to a clustered pattern in 1980 which was statistically significant, finally returning to a period of relative randomness thereafter.

For the whole study area, the mean age of the 258 mothers of twins was $27 \cdot 1$ compared with the mean age of 27.2 for the 107 mothers of twins $(41 \%)$ in the at risk areas-that is, FK2, 4-6. Of the 18 mothers aged 35 and over in the whole study area, seven $(39 \%)$ were in the at risk areas.
On both farms, the rates of twinning of calves increased dramatically in the late 1970s. In farm 1, where details of the numbers were available, the maximal rate was in 1983 (table 4); previously, the rate of twinning in this farm had been between $0 \%$ and $2 \%$. In farm 2 only the births of twin heifers had been recorded: in the 34 years from 1942 to 1975 only six sets of twin heifers had been born from a herd of about 35 cows and heifers; in the five years from 1976 to 1980 inclusive, by contrast, five sets of twin heifers were born to this herd whose numbers were declining rapidly, and which consisted of only 14 animals by 1981. 


\section{Discussion}

Different breeds of cattle have different rates of twinning, and the rate also increases with age. ${ }^{19}$ In general, however, the twinning rate is $0.5 \%$ for beef cattle and $2 \%$ for dairy cattle. ${ }^{20}$ Thus the sudden increases in rates in herds on the two farms were exceptional.

The analysis of the human twinning rates in the sectors, by ranking and spatial autocorrelation, indicated the late 1970 s and early 1980 s as the period when clustering became evident. These findings were consistent with the hypothesis that $\mathrm{PCHs}$ or other chemicals with biological actions similar to those of PCHs were introduced into the local environment in the late 1970s and were distributed by the light easterly winds.

The pattern of human twinning in the secondary at risk sectors (FK5 and 2) was the opposite of that in the primary at risk sectors, with comparatively high values for twinning present during 1976-9 in sectors FK 5 and 2 but not in FK5 (the more closely placed of these sectors to the incinerators) during 1980-3. Information has become available recently that, in a third farm in FK 5 very close to the incinerators, a threefold rise in twinning rates of cattle began in 1976. That these abnormalities appeared in this area before PCBs began to be burnt regularly at the chemical incinerator (in 1980) might have several explanations. PCBs may have been burnt on some occasions during the earlier years. Other substances with similar biological actions may have been released earlier-for example, PCHs and other complex chemicals may be liberated when plastics, waste oils, lubricant oils, or transformers are burnt under inappropriate conditions - that is, below $1100-1300^{\circ} \mathrm{C} .^{10}$ The height of the plume above ground level was reported to have been increased during the late 1970 s as a result of the raising of the fumestack and of the subsequent rotting of its cowl: these changes could have reduced the exposure to the fumes in sector FK5 (due to the "umbrella" effect) while increasing exposure to fumes in FK2 and in the higher ground of FK4 and 6, including the two farms there. A further explanation should be considered: if comparable biologically active pollutants were being emitted from the relatively low fumestack of the adjacent municipal incinerator, which is not under the control of the Industrial Pollution Inspectorate, these might have affected FK 5 during the earlier period; however, that explanation seems less likely because of the low frequency of twinning found there during the later period.

Associations have been noted elsewhere between environmental pollution on the one hand and mortality and obstetric events such as low birth weights and abnormal sex ratios on the other. ${ }^{21-25}$ But although the present findings were consistent with the hypothesis that environmental air pollution may have affected obstetric parameters of the local populations of people and animals, it would certainly be premature to attribute causality to this association between air pollution from incinerators and twinning. The genetic component of the twinning phenomena in these populations remains to be investigated (although the farmers have noted that the calf twinning occurred despite the use of several bulls for artificial insemination). Secondly, although the mean age of the twins' mothers in the at risk areas did not differ from the mean age in the area as a whole, other social factors affecting human twinning ${ }^{1418}$ could be confounding variables and have not yet been studied. Lastly, the possibility of statistical coincidence cannot be discounted. Nevertheless, the findings do indicate the advisability of undertaking further systematic epidemiological and environmental investigations of the Bonnybridge district, and of extending the studies to areas around chemical and municipal waste incinerators elsewhere.

We are grateful to Dr Susan Cole and her colleagues at the Information and Statistics Division of the Common Services Agency for providing the data for human twin births. We also acknowledge the interest and help of the Divisions of Obstetrics and Gynaecology at the Stirling Royal Infirmary and the Falkirk and District Royal Infirmary which will facilitate further studies on these circumstances.

\section{References}

1 Scottish Home and Health Department. Bonnybridge/Denny morbidity reviews: report of of independent review group. Edinburgh: SHHD, 1985. (Lenihan report.)

2 Reggiani G, Bruppacher R. Symptoms, signs and findings in humans exposed to PCBs and their derivatives. Environ Health Perspect 1985;60:225-32.

3 Warshaw R, Fischbein A, Thornton J, Miller A, Selikoff IJ. Decrease in vital capacity in PCB-exposed workers in a capacitor manufacturing facility. In: Nicholson WJ, Moore JA, eds. Health effects of halogenated aromatic hydrocarbons. Ann NY Acad Sci 1979;320:277-83.

4 Lloyd OLL, Lloyd MM, Lyster W. Bonnybridge/Denny: the Lenihan report. Environmental Health Scotland 1985;1:17.

5 Williams FLR. Re-Chem. Chemistry in Britain 1985;21:537.

6 Smith GH, Lloyd OLL. Soil pollution from a chemical waste dump. Chemistry in Britain 1986;22:139-41.

7 Lloyd OLL, Smith GH, Lloyd MM, Williams FLR, Hopwood D. Health hazards from chemicals in the environment: problems of evaluation. Chemistry in Britain 1987;23:31-2.

8 East of Scotland and West of Scotland Colleges of Agriculture. Report of an investigation into animal health problems in the Denny and Bonnybridge area of Stirlingshire. 1984.

9 Health and Safety Executive. Industrial air pollution. London: Health and Safety, 1984.

10 Royal Commission on Environmental Pollution. Managing waste: the duty of care. (11 th report). London: HMSO, 1985. (Southwood report.)

11 Rogan WJ, Gladen BC, Wilcox AJ. Potential reproductive and 
postnatal morbidity from exposure to polychlorinated biphenyls: epidemiological considerations. Environ Health Perspect 1985;60:233-9.

12 Rogan WJ, Gladen BC. Study of human lactation for effects of environmental contaminants; the North Carolina Breast Milk and Formula Project and some other ideas. Environ Health Perspect 1985;60:215-21.

13 Safe SH. Comparative toxicology and mechanism of action of polychlorinated dibenzo-p-dioxins and dibenzofurans. Annual Review of Pharmacology and Toxicology 1986;26:371-99.

14 Nylander PPS. The phenomenon of twinning. In: Barron SL, Thomson AM, eds. Obstetric epidemiology. London: Academic Press, 1983.

15 Hemon D, Berger C, Lazar P. Twinning following oral contraceptive discontinuation. Int J Epidemiol 1981;10:319-28.

16 Toibin C. Fear in the valley. Blackwell, Ireland: Magill, 1983: 26-38.

17 Cliff AD, Ord JK. Spatial processes: models and applications. London: Pion Press, 1981.

18 Bulmer MG. The biology of twinning in man. Oxford: Clarendon
Press, 1970.

19 Arthur GH, Noakes DE, Pearson H, eds. Veterinary reproduction and obstetrics. London: Bailliere Tindall, 1982.

20 Laing JA, ed. Fertility and infertility in domestic animals. London: Bailliere Tindall, 1979.

21 Lloyd OL, Lloyd MM, Holland YP, Lyster WR. An unusual sex ratio of births in an industrial town with mortality problems. $\mathrm{Br}$ J Obstet Gynaecol 1984;91:901-7.

22 Lloyd OL, Smith G, Lloyd MM, Holland Y, Gailey FA. Raised mortality from lung cancer and high sex ratios of births associated with industrial pollution. $\mathrm{Br} J$ Ind $\mathrm{Med}$ 1985;42: 475-80.

23 Lyster WR. Sex ratio of human births in a contaminated area. Med $J$ A ust 1977;1:532-4.

24 Beckman L. The Ronnskar smelter-occupational and environmental effects in and around a polluting industry in northern Sweden. Ambio 1978;7:226-31.

25 Office of Population Censuses and Surveys. Occupational reproductive epidemiology. Studies on medical and population subjects 50. London: HMSO, 1985.

\section{Destruction of manuscripts}

From 1 July 1985 articles submitted for publication will not be returned. Authors whose papers are rejected will be advised of the decision and the manuscripts will be kept under security for three months to deal with any inquiries and then destroyed. 